\title{
Aproximações à instabilidade temporal do contexto
}

\section{Approximations to the temporal instability of context}

\author{
Bruno Souza Leal \\ Doutor em Estudos Literários (UFMG) e pós-doutor em Ciências da Comunicação (Unisinos). Professor do Programa de Pós- \\ Graduação em Comunicação da UFMG. Coordenador do Núcleo de Estudos Tramas Comunicacionais. Pesquisador do CNPq. \\ <brunosleal@gmail.com>
}

\section{Carlos Alberto de Carvalho}

Doutor em Comunicação (UFMG) e pós-doutor em Ciências da Comunicação pela Universidade do Minho, em Portugal. Professor do Programa de Pós-Graduação em Comunicação da UFMG. Coordenador do Núcleo de Estudos Tramas Comunicacionais. Pesquisador do CNPq.

<carloscarvalho0209@gmail.com>

\section{RESUMO}

A noção de contexto, fundamental para uma série de perspectivas analíticas, ganha neste artigo problematizações que o situam em condição de instabilidade, particularmente definida a partir das conexões com a temporalidade. Buscamos evidenciar que, inicialmente na relação com as textualidades, as relações de contexto vão além da dicotomia "dentro" ou "fora" do texto, posto que marcadas pelas posições históricas, teóricas e epistemológicas das pesquisas e seus agentes na busca pela contextualização. Por seu turno, o contexto, normalmente visto como uma espécie de passado, pano de fundo ou moldura que auxiliaria na compreensão de textos, acontecimentos e outros fenômenos sociais e linguageiros, é visto em função de atravessamentos temporais complexos. Propomos, a partir do reconhecimento da instabilidade temporal do contexto, que o futuro, visto como antecipação, previsão ou outras estratégias para "dominá-lo", é a temporalidade quase sempre ausente das análises contextuais, quando deveria ser condição primordial.

\section{ABSTRACT}

The notion of context, which is fundamental to a series of analytical perspectives, gains in this article problematizations that highlights its instability, particularly defined from the connections with temporality. We seek to show that, in relation to textualities, context relations go beyond the dichotomy "inside" or "outside" of the text, since they are marked by the historical, theoretical and epistemological positions of the researches and their agents in the search for contextualization. For its part, the context, usually seen as a kind of past, background or frame that would assist in the understanding of texts, events, and other social and linguistic phenomena. Its seen as a function of complex temporal crossings. We propose, from the recognition of the temporal instability of the context, that the future, seen as anticipation, prediction or other strategies to "dominate" it, is the temporality often absent from the contextual analyzes, when it should be a primordial condition.

Keywords: Context. Textuality. Historicity.

Palavras-chave: Contexto. Textualidade. Historicidade.

\section{Introdução}

Nos últimos anos, contribuições teóricas de diferentes campos têm caracterizado e explorado o que se convencionou chamar de "instabilidade textual". Seja numa perspectiva filosófica, seja a partir de contribuições da linguística, da teoria literária, da antropologia, da geografia ou da comunicação, 
entre outros, o texto deixa de ser visto como um construto verbal acabado e passa a ser apreendido como um processo social, semiótico e comunicacional multimodal cujos limites e contornos são mais imprecisos que algumas perspectivas teóricas (que inclusive operam com dicotomias como dentro/fora) preconizam. A instabilidade do texto, ou passagem do texto à textualidade, como indicam os artigos reunidos por Leal, Carvalho e Alzamora (2017), traz como consequência a desestabilização de um outro termo, correlato a ele, mas frequentemente pacificado no modo como geralmente é abordado: o contexto.

Em geral visto como um pano de fundo, como um passado imediato do texto (ou do fenômeno, do acontecimento ou da situação tomada para reflexão), o contexto frequentemente nos desafia como operação (como contextualizar? O que cabe ou não cabe nessa contextualização? Até onde vai a construção desse contexto? etc.) mas não como problema teórico-metodológico. O esforço apreendido neste artigo é mais delinear alguns aspectos que configuram o "problema do contexto" sob mais de um ângulo, de modo a estimular a atenção aos desafios que ele impõe. Para isso, dado os limites deste artigo, realizamos aproximações a perspectivas teóricas que, guardadas suas diferenças, explicitam tanto a instabilidade temporal do texto e/ou do contexto como o papel decisivo do futuro, como expectativa (e em suas variadas formas), tem na sua configuração. Na reflexão aqui proposta, portanto, buscamos, a partir do reconhecimento da instabilidade do texto (e do processo comunicacional ao qual este se vincula), aproximarmo-nos desse problema, observando como o futuro é também parte da configuração do contexto, que, desestabilizado, apresenta-se como um tema desafiador e, porque não, fascinante.

\section{Da instabilidade do texto ao contexto}

Já na década de 1990, trabalhos como os de Silverman (1994), Jorge E. Gracía (1995, 1996), na filosofia, ou os compilados por Cohen (1997), no âmbito dos estudos literários, chamavam atenção para os impactos de perspectivas teóricas como o desconstrucionismo, os estudos de recepção, da comunicação, da crítica literária e mesmo da história tinham na instabilização do texto. Cohen, talvez de modo ainda conservador, sintetiza claramente um dos percursos que sustentam essa instabilidade:

Mais que imanente ao texto ou o produto da intenção de um autor, significados, numa visão alternativa, surgem das relações produzidas quando textos particulares são vistos em contextos específicos: à medida que versões textuais e contextos variam, o mesmo acontece 
com o espectro de significados possíveis. Assim, a essência do texto pode ser sua capacidade de ser re-ontologizado e re-interpretado infinitamente quando diferentes versões textuais e contextos são empregados.(...) A instabilidade textual é a contrapartida real e material da instabilidade de práticas interpretativas (Cohen, 1997, p. xxi-xxii, grifo do autor, tradução nossa)'.

Como se observa, textos se tornam instáveis quando se reconhece que eles estão integrados a processos de interpretação variáveis e historicamente situados, que inclusive contribuem para caracterizar qual é o texto (ou a versão textual, para usar a expressão de Cohen) com o qual se está em interação. Há, nessa perspectiva, uma clara implicação epistêmico-metodológica que, a partir do reconhecimento da complexidade dos processos interpretativos, traz importantes consequências para os modos como apreendemos e lidamos com as diferentes textualidades à nossa volta. Jorge Gracía (1995;1996), nesse sentido, acentua ainda mais a instabilidade textual e suas implicações para os modos como lidamos com os fenômenos comunicacionais quando observa a heterogeneidade constitutiva de qualquer construto semiótico. "Texto", menos que uma contração da expressão "texto verbal", é, na perspectiva do filósofo, uma emergência composta por uma diversidade de "entidades", de qualidades semióticas distintas, que em razão de uma ação comunicativa são articuladas para constituir uma textualidade. A opção pela palavra "entidade" é importante para Gracía para acentuar que textos podem ser compostos por uma variedade de materiais que assumem, numa situação comunicativa, o papel de signo, mesmo que não sejam tradicionalmente (como os signos linguísticos) já convencionados como tal.

Já Gonzalo Abril (2007), em clara chave semiótico-cultural, se inspira em Bakhtin e Peirce para afirmar que "[...] texto não é uma entidade estável em uma encruzilhada de relações intertextuais, mas um processo, um devir de deslizamentos, hibridações e osmoses, entre fragmentos textuais prévios, linguagens e perspectivas semióticas [...]"2 (Abril, 2007, p. 82, tradução nossa). As

\footnotetext{
1 No original: Rather than immanent in the text or a product of an author's intentions, meanings, in this alternative view, arise from the relations produced when particular texts are viewed from particular contexts: as textual versions and contexts change, so may the range of possible meanings. Thus the essence of text may be their ability to be re-ontologized and re-interpreted endlessly as diferent textual versions and contexts are employed. [...] Textual instability is the very real, very material counterpart of the instability of interpretative practices.

2 No original: [...] texto no es uma entidade estable en uma encrucijada de relaciones intertextuales, sino un processo, um devenir de solapamentos, hibridaciones y ósmosis entre fragmentos textuales prévios, lenguajes y perspectivas sociosemióticas [...].
} 
implicações epistêmico-metodológicas desse entendimento acerca dos textos são exemplificadas por Abril a partir do trabalho etnográfico, uma vez que o texto etnográfico não precede ao trabalho do pesquisador, mas se apresenta como seu produto. Há um processo inevitável de apropriação e tradução no trabalho etnográfico, que “...produz determinados textos que medeiam entre uma experiência de observação e interação e uma experiência de leitura (e de registro, de arquivo, controle, etc) em outro contexto cultural: o meio acadêmico..."3 (Gonzalo Abril, 2007, p. 85)

Aquilo que afirma, a título de exemplo, Gonzalo Abril é tema de reflexão de antropólogos como Bauman e Briggs (2006), que diante do caráter performativo dos processos culturais, observam a dinâmica textual peculiar dos trabalhos etnográficos. Para eles, um processo cultural qualquer é necessariamente tornado texto, entextualizado, pela ação do pesquisador, para a seguir ser descontextualizado ao circular no ambiente acadêmico e recontextualizado pelos seus interlocutores. Longe de ser simples, esse processo é eivado de implicações éticas, teóricas, epistêmicas e metodológicas bastante desafiadoras. Uma dessas consequências é explicitamente anunciada por Bauman e Briggs, para quem os "[...] estudos de performance estão no meio de uma reformulação radical onde 'texto', 'contexto' e a distinção entre eles estão sendo redefinidos" (Bauman e Briggs, 2006, p. 199).

A instabilidade do texto, portanto, traz consigo a desestabilização do contexto, num movimento duplo de ruptura: com uma concepção pouco problematizadora do contexto e de suas premissas positivistas. Bauman e Briggs são claros nesse aspecto. Por um lado, não existe "[...] forma alguma de saber quando um conjunto adequado de fatores contextuais é constituído" (Bauman e Briggs, 2006, p. 199), ou seja: o que (porque, de que modo) se pode incluir no "contexto" e qual (se há) o limite nessa inclusão. Por outro lado, “...já que é obviamente impossível apontar todos os aspectos do contexto, o pesquisador torna-se o juiz que estabelece o que merece ser incluído" (Bauman e Briggs, 2006, p. 200). Com isso,

[...] definições positivistas constroem o contexto como um conjunto de condições externas ao discurso e que existem a priori e independentemente da performance. Isto reduz a habilidade do analista de discernir como os próprios praticantes determinam quais aspectos da interação social e mandamento são relevantes e também

3 No original: [...] produce determinados textos que median entre una experiencia de observación y interacción y uma experiencia de lectura (y de registro, de archivo, control, etc) enotro contexto cultural: el médio acadêmico [...]. 
oculta a maneira como a fala dá forma ao cenário, frequentemente transformando as relações sociais. Reificar "o contexto" também preserva implicitamente a premissa que o significado emerge essencialmente de conteúdos proposicionais livres do contexto, que são então modificados ou esclarecidos pelo "contexto". (Bauman; Briggs, 2006, p. 200)

O que implica não reificar o "contexto"? Que dimensões apresenta a sua instabilidade? Essas perguntas, que nascem como consequência inevitável de um conjunto de trabalhos e perspectivas teóricas que instabilizam também o texto, são certamente instigantes e desafiadoras. Nesse quadro, este artigo traz uma reflexão sobre uma das dimensões mais instigantes dessa instabilidade, 0 do tempo. Afinal, o contexto, como observam Bauman e Briggs (2006), parece inicialmente preceder, anteceder o texto. Se este é um processo, um construto cujos limites são imprecisos, como observam, no campo da comunicação, os estudos coligidos por Leal, Carvalho e Alzamora (2017), o contexto pode ser visto então apenas como um conjunto de relações a partir do qual o texto (ou o fenômeno da comunicação) emerge?

\section{Do contexto reificado à expectativa do futuro}

Segundo o dicionário Houaiss (2017), a palavra contexto tem como raiz etimológica contextus, doverbocontexere, quesignifica entrelaçar, reunirtecendo. Já a definição em português da palavra abrange, segundo o mesmo dicionário, quatro acepções, duas delas de base linguística. Assim, "contexto" é o mesmo que "ambiente", ou seja, a "inter-relação de circunstâncias que acompanham um fato ou situação". É também "o texto que precede ou sucede a determinada palavra, frase ou texto" (Houaiss, 2017), contribuindo para seu significado. Essa acepção está articulada à última definição: "conjunto de condições de uso da língua" (Houaiss, 2017), envolvendo os comportamentos linguístico e social, o emissor e o receptor". Em dicionários mais especializados, não encontramos muitas diferenças no entendimento acerca do que é o contexto. Para citar um exemplo, no bastante conhecido Dicionário de Semiótica de Greimas e Courtés (2008), a primeira definição de contexto, guardada a diferença lexical, remete com precisão à do dicionário brasileiro: "Chama-se contexto o conjunto do texto que precede e/ou acompanha a unidade sintagmática considerada e do qual depende a significação" (Greimas e Courtés, 2008, p. 97).

Inicialmente, chama a atenção nessas definições pelo menos três aspectos recorrentes. Primeiro, o caráter secundário do contexto, que, mesmo sendo imprescindível à significação, é um "acompanhante", um complemento 
ao protagonismo do texto, da situação ou fato alvo da observação ou análise. Em segundo lugar, o contexto, precedendo ou sucedendo aquilo que recebe o foco de nosso olhar, é estático, ou seja, é um estado de coisas, que, mesmo entramado, inter-relacionado, se apresentaria identificável e estabilizado quando recebe nossa atenção. Por fim, esse estado de coisas, mesmo estável, tem uma sutil diversidade temporal, pois ora é o passado (do texto, do fato, da situação), ora um presente (acompanhando-os e envolvendo seus agentes), ora é o futuro. É como se o contexto pudesse ser posto ou apreendido num certo momento da situação comunicativa, conforme as especificidades desta, ou das necessidades daqueles que buscam entende-la. Em todos os casos, não parece ser impertinente ou redutora, pelo que foi visto até aqui, a "tradução" recorrente de contexto como "pano-de-fundo" que precede, sucede ou é contemporâneo ao que buscamos entender.

No entanto, essa diversidade temporal surge como um problema quando observamos mais atentamente as definições acima. Afinal, não é preciso recorrer a obras clássicas como as de Santo Agostinho, por exemplo, para reconhecermos que a experiência temporal humana não é simples ou linear, a ponto de passado, presente e futuro se apresentarem assim desconectados ou seccionados nas diferentes situações de nossas vidas. Essa desconexão advém certamente de um gesto de conhecimento que, no esforço de compreender texto, situação ou fato, produz a secção da complexidade temporal que nos envolve. Como observam Lluis Duch e Alberto Chillón (2012), trata-se de um paradoxo inerente ao processo de tomar algo como um "fato social", intrinsicamente vinculado a um processo de objetivação que sobrepõe e articula, nos termos dos autores, a "objetividade epistemológica" à "objetividade ôntica". Contrariando Durkheim e em estreito diálogo com Schutz, Berger e Luckman, Duch e Chillón afirmam:

[...] o animal symbolicum apenas dotada para representar seu mundo com a objetividade que tanto proclama e anseia encontrase fatalmente condenado a gestar objetivações: não brutos acontecimentos naturais, mas fatos de um novo cunho, miudezas de realidade flamejante forjados mediante a dialética interiorização e exteriorização das objetivações já instituídas - que a sua vez acabam forjando dados. (Duch e Chillón, 2012, p. 380, tradução nossa) ${ }^{4}$

4 No original: [...] el animal symbolicum, apenas dotado para representar su mundo con la objetividad que tanto proclama y anhela, se halla fatalmente abocado a gestar objetivaciones: no brutos acaeceres naturales, sino hechos de un nuevo cuño, retazos de flamante realidad forjados mediante la dialéctica interiorización y exteriorización de la objetivaciones ya instituidas - que a su vez acaban fraguando hasta devenir dados. 
Isso é dizer, portanto, que o posicionamento do contexto no presente, no passado ou no futuro resulta menos das qualidades e características de determinados fatos, situações e/ou textos que das escolhas que envolvem o conhecimento que queremos obter e produzir acerca deles. Nesse sentido, a suposta estabilidade do contexto, apreendido como um pano-de-fundo, é antes o resultado desse gesto de saber que sua qualidade óbvia. Isso fica mais claro quando se observa, em quaisquer das definições que tomemos para o termo, que essa eventual estabilidade está diretamente ligada se não ao apagamento, ao menos ao menosprezo da ação humana presente nas situações, nos fatos e nos textos. Aliás, nas definições que recuperamos acima um conjunto heterogêneo de expressões (como "uso", "inter-relação", 'significação") que vinculam contexto ao agir humano, que é congelado quando configurado por termos que sugerem circunstâncias encerradas e findas ("situação", "texto", "fato"), indicando com clareza os limites teóricos e epistemológicos das percepções do contexto como algo estável, ou ainda, independente dos modos como agentes de uma investigação em particular.

Diferentes perspectivas teóricas, em mais de um campo do saber, apontam, porém, exatamente para o oposto: nem a situação, nem o acontecimento, ou fato, como mais comumente encontramos nos conceitos vistos acima, nem o texto são ocorrências pontuais, cujos limites se dão a ver de forma precisa. Exatamente porque emergem vinculadas a "inter-relações" humanas, semióticas e sociais, todos têm uma natureza processual, na qual se fazem presentes múltiplas dimensões temporais. Nesse sentido, a palavra contexto adquire uma qualidade dinâmica e instável, como se pode apreender nas reflexões de Lluis Duch y Alberto Chillón:

Inevitavelmente, quem se refere à relacionalidade como atributo essencial do homem está se referindo, na realizada, a sua construção espaço-temporal, a qual, incessantemente, deve contextualizar-se como consequência da mobilidade intrínseca do trajeto humano. Por conseguinte, pode-se afirmas que, por causa da relacionalidade como atributo fundamental do homem, este sempre se acha submetido, para o bem ou para o mal, à obra do tempo. [...]. Brevemente: somos, ao mesmo tempo e sem solução de continuidade, salvos e pervertidos, filhos e engendradores de um tempo. Nós o expressamos e, de alguma maneira, ele nos expressa mediante os simbolismos que têm vigência em nossa tradição cultural (Duch; Chillón, 2012, p. 131, tradução nossa) $)^{5}$.

5 No original: Inevitablemente, quien se refiere a la relacionalidad como atributo esencial del hombre está se refiriendo, en realidad, a su construcción espacio-temporal, la cual, incesantemente, debe contextualizarse como consecuencia de la movilidad intrínseca del 
Ochamadoà contextualização que sefazpresenteno pensamento de Duch e Chillón está, como se vê, intimamente vinculado à experiência da mobilidade fundamental do trajeto humano e das múltiplas dimensões temporais, de passados, presentes e futuros, que permeiam nossas vidas. Menos que um "pano de fundo, contexto" passa a ser um esforço de apreender ao menos parte dessas inter-relações que se apresentam em constante rearticulação no nosso agir no mundo. Disso resulta que as diversas formas de viver o futuro, uma vez que condicionante, destino e elemento propulsor de nossas ações, é tão parte desse esforço de contextualização quanto nossas formas de acessar passados e presentes. Longe do paradoxo do "tempo jamais a ser vivido", o futuro, é ele mesmo um fenômeno socialmente vivenciado e significativo.

Para além de formas já bastante reconhecidas, como a utopia e o progresso, o futuro se inscreve no nosso cotidiano social, informando nossos contextos, de modos bem peculiares. Arjun Appadurai (2013) é um dos autores que reconhece a importância do futuro na composição de nossas ações cotidianas, numa investigação exploratória que afirma, aliás, que as ciências sociais nunca foram muito capazes de alcançar essa importante força na vida humana. Buscando, por um lado, escapar das armadilhas de concepções que tomam o futuro como algo intangível ou inefável e, por outro, apreendendo-o como um fenômeno social que implica indivíduos e coletivos (sociedades, classes, gerações, grupos sociais etc.), Appadurai identifica ao menos três formas do futuro como um "fato cultural": imaginação, aspiração e antecipação. Essas formas organizam, condicionam e se inscrevem no agir humano, contribuindo para que este adquira forma e sentido.

Por imaginação, Appudarai entende uma "energia cotidiana", socialmente constituída e vinculada à memória, capaz de orientar processos e projetos coletivos e individuais. A imaginação aqui adquire o caráter de repertório em constante construção, que não apenas dá forma ao que há e ao que que foi, mas também de mapear o que poderá ser, contribuindo para estabelecer os limites (para o indivíduo e o coletivo a que pertence) entre o possível e o impossível, o provável e o improvável de acontecer e de ser feito. O caráter processual e in progress dessa imaginação reconhece nela um elemento de negociação, de contínua readequação, à medida que acontecimentos se sucedem, que a memória ressignifica e, consequentemente, projeta novos futuros. Diz

trayecto humano. Por consiguiente, puede afirmarse que, a causa de la relacionalidad como atributo fundamental del hombre, éste siempre se halla sometido, para bien o para mal, a la obra del tiempo [...] Brevemente: somos, al mismo tiempo y sin solución de continuidad, salvados y pervertidos, hijos y engendradores de un tiempo: lo expresamos y, de alguna manera, nos expresa mediante los simbolismos que tienen vigencia en nuestra tradición cultural. 
Appadurai:" [...] o arquivo pessoal de memórias, tanto material quanto cognitivo, não é primariamente sobre o passado, mas serve para proporcionar um mapa para negociar e moldar novos futuros"(Appadurai, 2013, p. 288, tradução nossa). ${ }^{6}$

A aspiração se articula e se distingue, por sua vez, da esperança, vista não como uma emoção humana, mas como a capacidade de aspirar a algo, sejam melhores condições de vida, o fim (ou a suavização) de situações de opressão, a superação de adversidades etc. Seu caráter político, portanto, é ainda mais evidente que o da imaginação, mesmo quando a aspiração é conservadora (manter as coisas como estão) ou reacionária (de recuperação ou retorno a condições que se alteraram). A "capacidade de aspirar a algo" certamente está presente em qualquer agrupamento humano, mesmo que seja na forma de utopia ou de projeções míticas ("...um mundo sem violência", "o paraíso" etc.). No entanto, alerta Appadurai (2013), sua força é basicamente local, uma vez que está vinculada a formas de linguagem, a valores sociais, histórias e normas institucionais bastante específicos.

Já a terceira forma do futuro "como fato cultural" identificada por Appadurai (2013) adquire um estatuto duplamente ambivalente. Por um lado, a antecipação está diretamente articulada ao risco, ou seja, envolve a capacidade (em articulação com a imaginação e a aspiração) de agir no presente para construir um futuro desejável, prevendo, mesmo parcialmente, também os perigos dessa ação, de seus desdobramentos e os imprevistos. Nenhuma antecipação pode ser pensada, portanto, sem ter o risco como sua contrapartida. Isso leva, então, à segunda ambivalência da antecipação, que envolve, segundo Appadurai (2013), uma tensão constante entre éticas "da possibilidade" e da "probabilidade". Diz ele:

Por ética da possibilidade, eu me refiro àqueles modos de pensar, sentir e atuar que aumentam os horizontes de esperança, que expandem o campo da imaginação, que produze maior equidade naquilo que eu chamei de capacidade de aspirar, e que alargam o campo da cidadania informada, criativa e crítica [...]. Por ética da probabilidade, eu me refiro àqueles modos de pensar, sentir e atuar que seguem o que lan Hacking chamou de "a avalanche dos números", ou o que Michel Foucault viu como os perigos capilares do regime moderno de diagnóstico, contagem e contabilidade. Eles são geralmente ligados ao crescimento do capitalismo de cassino que lucra com a catástrofe e que tende a apostar no desastre. Esta última ética é tipicamente vinculada a formas amorais do capital global,

6 No original: [...] the personal archive of memories, both material and cognitive, is not only or primarily about the past, but is about providing a map for negotiating and shaping new futures 
estados corruptos e aventureiros privatizados de toda variedade (Appadurai, 2013, p. 295, nossa tradução)․

Pelo excerto acima, fica clara novamente a dimensão política que o futuro, como um organizador de nossas ações, ou seja, como parte do nosso "contexto", adquire para Appadurai (2013). A passagem da imaginação para a aspiração e daí para a antecipação correspondente a uma intensificação desse caráter político nos horizontes que se delineiam à medida que agimos, ou seja, à medida que vivenciamos e atuamos em situações, fatos e textos.

\section{Contexto, acontecimento, historicidade e comunicação}

A instabilidade temporal do contexto, se por um lado chama atenção para a impossibilidade da sua apreensão fora das tramas temporais, por outro nos diz, a partir dos termos de Appadurai, que o futuro, como desejo, como imaginação, como projeção e como projeto antecipador é um dos aspectos que as noções tradicionais de contexto têm relegado a segundo plano. Passamos, assim, da perspectiva imobilizada/imobilizadora do contexto, metaforicamente identificável pela fotografia, para a noção de contexto como algo dinâmico, contraditório, movente para o futuro, cuja metáfora pode ser a da imagem em movimento, em perspectiva multidimensional.

Parece-nos que o complemento teórico que falta, que implica ao mesmo tempo um esforço metodológico para a sua articulação com a noção de contexto, é o acontecimento em suas complexas relações com as textualidades, e dessas para os processos e produtos comunicacionais. A perspectiva do fato que é frequente nas problematizações do contexto, identificada ou não com a noção durkheimiana clássica do "fato social", deixa escapar precisamente aquilo que o conceito de acontecimento requer (Quéré, 2005; Bennetti, Fonseca, 2010; Leal, Antunes; Vaz, 2011; Vogel, Silva; Meditsch, 2012; Sodré, 2012; entre outros): sua condição de historicidade, sua radical inserção nas tramas das temporalidades. Se o fato é, na maioria das abordagens, da ordem do "presenteísmo", entendido

7 No original: by the ethics of possibility, I mean those ways of thinking, feeling, and acting that increases the horizons of hope, that expand the field of imagination, that produce greater equity in what I have called the capacity to aspire, and that widen the field of informed, creative, and critical citizenship. [...] By the ethics of probability, I mean those ways of thinking, feeling, and acting that flow out of what lan Hacking called 'the avalanche of numbers', or what Michel Foucault saw as the capillary dangers of modern regime of diagnosis, counting, and accounting. They are generally tied to the growth of a casino capitalism which profits from catastrophe and tends to bet on disaster. This latter ethics is typically tied up with amoral forms of global capital, corrupt states, and privatized adventurism of every variety. 
como a tentativa de fixar somente no presente as condições de sua existência, intimamente relacionado, portanto, à ideia de factualidade, das relações causais lineares, o acontecimento é da ordem das dinâmicas socioculturais, das disputas de sentido, dos jogos de poder e das complexas redes de construção textual, sejam elas investigadas sob as perspectivas discursivas, narrativas ou outros modos de pensar e problematizar as textualidades.

Encontramos em Paul Ricoeur (1994; 1997), especialmente a partir do conceito de tríplice mimese, os termos que permitem a elucidação da equação acontecimento-comunicação-temporalidades-contexto. É sabido que para Ricoeur a narrativa é aquilo que, resultado da tessitura da intriga que põe em jogo acontecimentos, com seus agentes e padecentes articulados nas relações passado-presente-futuro, permite a mínima apreensão do tempo. Se este está fadado às aporias, seja quando visto sob as perspectivas fenomenológicas, seja quando escrutinado pela via física, cronológica, restaria à narrativa "tornar o tempo humano" (Ricoeur, 1994), progressão que lhe destinaria também ser a "guardiã do tempo" (Ricoeur, 1997). Tornado humano, o tempo implica, para a sua compreensão, verificar o contexto em que cada acontecimento com suas personagens teve origem e desenvolvimentos. Se o exercício parece indicar um círculo vicioso de idas e vindas improdutivas, é somente pelo gesto interpretativo, pela hermenêutica implicada na análise narrativa, que ele pode se tornar virtuoso, pois a cada movimento é o próprio contexto que se modifica, inclusive por dinâmicas da comunicação entre os diversos agentes implicados no acontecimento e nas estratégias de narrá-lo. Além do mais, inscritas na tríplice mimese, as narrativas são, precisamente, a via pela qual as aporias do tempo, embora não cessem, pois restará sempre uma inescrutabilidade das relações passado-presente-futuro, ao menos podem ser mitigadas pela possibilidade de compreendermos o tempo em termos de historicidade, implicando memória e esquecimento, características únicas da espécie humana.

A virtuosidade do círculo hermenêutico começa seus termos quando as narrativas são verificadas em suas articulações temporais com a tessitura das intrigas que a compõe. Segundo Ricoeur (1994), toda narrativa contém em si uma espécie de "síntese do heterogêneo", "a concordância discordante" que une tempos e acontecimentos distintos e mesmo conflitantes entre si, mas cuja articulação permite atribuir inteligibilidade a uma história narrada, considerando ainda as personagens em ação e suas múltiplas vivências de acontecimentos transcorridos ao longo de uma vida. O contexto, por essa via, não é reivindicado diretamente, pois ele não se revela à maneira de uma superfície plana. Antes, tem diversos estágios de latência dispersos nas relações passado-presentefuturo. Mas de que modo, precisamente, é possível fazer o contexto "emergir"? 
Voltemos à tríplice mimese, destacando que para Paul Ricoeur mimese não é imitação, mas ação, ainda que a ação imitativa, por exemplo, segundo a fórmula "a arte imita a vida". Se mimese não é imitação, mas ação, a tríplice mimese é a proposição de que toda narrativa é a mediação do gesto figurador de uma história, o ato de narrar mais facilmente identificado entre um mundo prefigurado, cujas condições éticas, morais, simbólicas etc. antecedem qualquer narrativa, e a refiguração, momento em que a leitura potencialmente modifica a narrativa proposta, assim como a própria pessoa que a lê. Nota-se, portanto, que mimese I, o mundo prefigurado, constitui na visão mais tradicional o contexto que explicaria um determinado texto ou acontecimento, correspondendo à metáfora da fotografia a que aludimos.

No entanto, e já nos encaminhando para a metáfora da imagem em movimento, o momento de figuração, ou mimese II, ao mediar o mundo prefigurado com o mundo reconfigurado representado pela leitura e interpretação, ato hermenêutico por excelência que é mimese III, tanto nos faz ver o gesto narrativo como ele também compondo o contexto, como ainda deixa à vista o momento da leitura como outro componente contextual importante, pois a ação narrativa não cessa de acontecer. Se pensamos nas implicações do acontecimento apanhado pelas narrativas, temos aqui a explicitação dos jogos de poder e disputas de sentido que fazem com que ele esteja em permanente transformação pela interpretação, que é ainda ação de projetá-lo para o futuro, à maneira de uma equação que sinteticamente resumiríamos na noção de que interpretar o acontecimento é parte das tentativas de assegurar desdobramentos e consequências para o adiante, não mais pela tradição adivinhatória, mas pelo planejamento estratégico do que poderá vir a ser.

O acontecimento, para Ricoeur, tanto é aquilo que "motiva" uma narrativa, quanto é aquilo que por ela é incorporada. Em sua proposição,

Limitemo-nos aos postulados epistemológicos implícitos no uso corrente do termo acontecimento - singularidade, contingência, separação - e empenhemo-nos em reformulá-los no quadro de nossa teoria da intriga, sob o título de mimese ll. Essa reformulação procede da conexão primordial entre acontecimento e narrativa por meio da intriga. (...), os próprios acontecimentos recebem uma inteligibilidade derivada de sua contribuição para a progressão da intriga. Daí resulta que as noções de singularidade, de contingência e de separação devem ser seriamente modificadas (Ricoeur, 1994, p. 294-295, grifo do autor). 
Das noções modificadas pela relação entre acontecimentos e intriga, a de separação é a mais produtiva para nossos propósitos, não somente porque ela ressalta a integração entre os dois termos, mas sobretudo porque inscreve o acontecimento inequivocamente na historicidade. Resulta daí que recuperar um acontecimento é operação complexa que não prescinde da busca por rastros, vestígios, arquivos, documentos, testemunhos e demais artefatos das operações implicadas nas tramas da historicidade (Ricoeur, 2007). O circuito hermenêutico representado pela noção da tríplice mimese, por consequência, implica um leitor das narrativas que tanto pode ser o fruidor com objetivos mais voltados para o prazer estético, quanto o investigador interessado e munido de aparatos conceituais e metodológicos. Quaisquer que sejam as características e objetivos desse leitor a ideia de que, diante dos acontecimentos, somos agentes e pacientes, impede a naturalização da relação, e especialmente, para os nossos propósitos, situa o futuro como a temporalidade geralmente excluída das noções de contexto. A destacar, ainda, que a dialética agir/sofrer o acontecimento nos torna interessados nos desdobramentos dele, significando a adoção de ações com vistas a alcançar tal objetivo, que implica em tentativas de "moldar" o acontecimento a nosso favor ou, no mínimo, tentar mitigar seus efeitos negativos sobre nós.

Outras tradições de pesquisa também nos informam sobre o caráter primordial do futuro em nossas ações e relações com os acontecimentos, a exemplo do que propõe Reinhart Koselleck acerca das relações entre experiência e expectativa, segundo a lógica do espaço de experiência e do horizonte de expectativa.

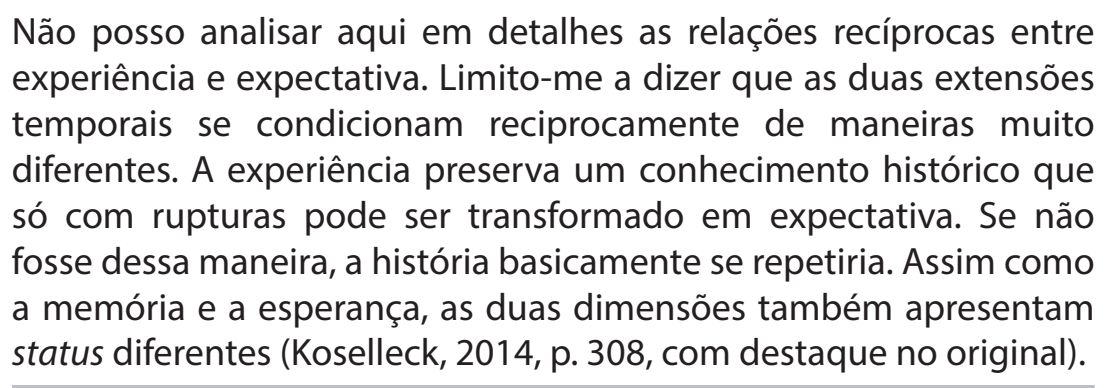

O espaço de experiência como referência para o horizonte de expectativa situa o presente como o lócus da articulação do futuro projetado, em que estão em jogo relações mais complexas do que, por exemplo, a máxima "conhecer o passado para evitar seus equívocos no futuro". Em complementação com a proposição de Appadurai do futuro como fato social, como componente cultural, as noções de Koselleck nos alertam também que, a partir de um determinado 
sentido da modernidade, alcançar o futuro passou a ser o equivalente de uma ideia de progresso, que tanto sinaliza para a aceleração da chegada do futuro, em termos de avanços técnicos, quanto implica componentes ideológicos segundo os quais o progresso implica visões políticas conflitantes entre si.

Como vai ficando mais evidente a cada aproximação com as noções de acontecimento, narrativa, temporalidade e historicidade, a ação humana é central para qualquer perspectiva de contexto. Se pensamos na ação, segundo proposição de Hannah Arendt (2014), como atividade humanizadora do ser humano, em contraposição com a fabricação, que pode assumir caráter desumanizador, por exemplo, nas relações de produção mecanizada ou nas formas de trocas comerciais em que o dinheiro apaga as energias necessárias para a concretização da mercadoria, o contexto reveste-se de carga ética e moral. O homem que age com vistas ao futuro é aquele dotado da capacidade de agência, que pela promessa (Arendt, 2014; Ricoeur, 1991; 2008; 2008a) assume o compromisso com aquilo que é prometido, segundo a fórmula "eu sou capaz". Ser capaz de prometer, de projetar o e para o futuro é situar a espécie humana como aquela que difere das demais formas de vida pela necessidade de reconhecer sua ambiência, seus espaços vitais, seus contextos, tornando-se apta para ações em fina articulação passado-presente-futuro. Se a promessa é gesto ético e político de compromisso com um determinado futuro, ela não deixa de ser também um olhar retrospectivo sobre o passado, em que este pode ser também modificado a partir de novas significações dadas aos acontecimentos que nele ocorreram. Para não ir longe, pensemos nas polêmicas em torno da Comissão da Verdade no Brasil, em permanente luta para definir quais foram as consequências e responsabilidades das torturas e demais formas de violências físicas e simbólicas perpetradas pela ditatura civil militar que governou o país do golpe de 1964 a 1985. Os trabalhos da Comissão envolvem um tipo de promessa sobre o futuro em simultâneo a reinterpretações do passado a partir das vítimas, e não dos algozes. Espera-se, como corolário, que o futuro não seja a ameaça ou a projeção de novos projetos autoritários.

Nossas promessas são compartilhadas, tornadas públicas, pela comunicação, desde a forma mais elementar - e nem por isso destituída de monumental complexidade - da interlocução face a face por meio da língua e das formas verboaudiovisuais, até as formas midiáticas. Nessas últimas, às promessas tradicionais, some-se a própria perspectiva de que suas estratégias de disseminação espaço-temporais materializariam o cumprimento da promessa de democratização dos fluxos comunicacionais, quando não representariam o próprio arquétipo contemporâneo do "progresso", com suas variadas modalidades de aceleração do tempo e conteúdos ideológicos contraditórios. 
Somados, tais elementos constituem, para a comunicação midiática, elementos indispensáveis a análises que tenham o contexto como um desafio teóricometodológico, inclusive com vistas às desmistificações de noções como "progresso" e "democracia/democratização".

Da introdução da noção de acontecimento apanhado por tramas discursivas, narrativas e de outras ordens linguageiras ao conceito de comunicação, pensada como as trocas simbólicas por meio das textualidades verboaudiovisuais que nos permitem os contatos, o estar juntos, assim como os afastamentos, os dissensos, os mal-entendidos, o contexto se avoluma em complexidade. Se o primeiro esforço é sempre pensar a comunicação como prática cotidiana de interação e mediação nas trocas interindividuais, como parece ser o que move os estudiosos dos textos que se veem diante do desafio imposto pelo contexto, temos ainda as diversas modalidades da comunicação midiática cujos esforços de compreensão são também atravessados pelas noções de acontecimento e contexto.

Se etimologicamente a palavra contexto aponta para entrelaçamento, para unir tecendo, sua proximidade com as narrativas - que resultam da tessitura da intriga em seus liames com o tempo e as temporalidades - fica ainda mais forte. Narrar nãoésomente enredar-seem múltiplos contextos, comoa noção de tríplice mimese permite vislumbrar, mas é um dos elementos constitutivos do contexto. Nessa complexa interconexão entre passado, presente e futuro, em que o último é elemento vital que impele as ações humanas, especialmente sob a forma da promessa que faz emergir o compromisso ético e político de cumprimento do prometido, não se trata de buscar um "antes" e um "depois" do texto, um "dentro" e um "fora" do texto, mas de perceber as textualidades simultaneamente como o que contém e projeta o "antes" e o "depois", o "dentro" e o "fora".

Dialeticamente, portanto, o contexto está, simultaneamente, antes e depois do texto, dentro e fora dele. Mas, pela reflexão que estamos propondo, sua complexidade temporal não se encerra na recuperação do passado que torna possível os antecedentes contextuais, somado às condições do presente em que determinado acontecimento, narrativa, produto ou processo comunicacional ganharam existência. O futuro, nos termos aqui apresentados, é elemento indispensável para que a metáfora do contexto mude da imobilidade da fotografia que registra e congela um instante para a metáfora da imagem em movimento, capturada de forma multidimensional, permitindo tornar visíveis as ações humanas a partir da noção da dialética agir/sofrer o acontecimento. 
Referências

ABRIL, Gonzalo. Análisis crítico de textos verbovisuales. Madri: Síntesis, 2007. Cultura visual: de lo semiótico a lo político. Madri: Plaza y Valdés, 2016.

APPADURAI, Arjun. The future as cultural fact. Londres: Verso, 2013.

ARENDT, Hannah. A condição humana. Rio de Janeiro: Forense Universitária, 2007.

BAUMAN, Richard; BRIGGS, Charles. Poética e performance como perspectivas críticas sobre a linguagem e a vida social. Ilha - Revista de Antropologia, Florianópolis, UFSC, v. 8, n. 1-2, p. 185-229, 2006.

BENNETTI, Márcia; FONSECA, Virgínia (org). Jornalismo e acontecimento: mapeamentos críticos. Florianópolis: Insular, 2010.

DUCH, LLuis; CHILLÓN, Alberto. Un ser de mediaciones. Barcelona: Herder, 2012.

COHEN, Philip (org.). Texts and textuality. Nova lorque: Routledge, 1997.

GRACÍA, Jorge E. A theory of textuality. Nova lorque: State of New York University Press, 1995.

. Texts: Ontological Status, Identity, Author, Audience. Albany: State University of New York Press, 1996.

GREIMAS, Algidas; COURTÉS, J. Dicionário de Semiótica. Campinas: Contexto, 2008.

HOUAISS, A. Grande dicionário Houaiss. Disponível em: https://houaiss.uol.com.br/ pub/apps/www/v3-0/html/index.htm\#0. Acesso em: 26 mar. 2017.

KOSELLECK, Reinhart. Estratos do tempo: estudos sobre história. Rio de Janeiro: Contraponto/PUC-Rio, 2014.

LEAL, Bruno; CARVALHO, Carlos; ALZAMORA, Geane (orgs). Textualidades mediáticas. Barcelona: Editorial UOC, 2017.

LEAL, Bruno; ANTUNES, Elton;VAZ, PauloBernardo (orgs.).Jornalismo eacontecimento: desafios metodológicos. Florianópolis: Insular, 2011

QUÉRÉ, Louis. Entre o facto e sentido: a dualidade do acontecimento. Trajectos, Revista de Comunicação, Cultura e Educação, Lisboa, ISCTE-IUL, n. 6, p. 59-75, 2005.

RICOEUR, Paul. O si mesmo como um outro. Campinas: Papirus, 1991.

Tempo e narrativa - Tomo I. Campinas: Papirus, 1994.

Tempo e narrativa - Tomo III. Campinas: Papirus, 1997. 
A memória, a história, o esquecimento. Campinas: Editora da Unicamp, 2007.

O justo 1: a justiça como regra moral e como instituição. São Paulo: Martins Fontes, 2008.

0 justo 2: justiça e verdade e outros estudos. São Paulo: Martins Fontes, 2008a.

SILVERMAN, Hugh J. Textualities - between hermeutics and deconstruction. Nova lorque: Routledge, 1994.

SODRÉ, Muniz. A narração do fato. Petrópolis: Vozes, 2012.

VOGEL, Daisi; SILVA, Gislene; MEDITSCH, Eduardo (orgs). Jornalismo e acontecimento. v. 4. Florianópolis: Insular, 2012.

Recebido em: 3/4/2017

Aceito em: 20/4/2017

Endereço dos autores:

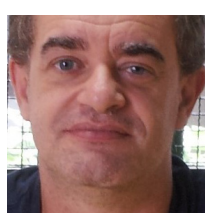

Bruno Souza Leal <brunosleal@gmail.com>

Programa de Pós-Graduação em Comunicação da UFMG

Avenida Antônio Carlos, 6.627 - Campus Pampulha

31270-901 - Belo Horizonte (MG) - Brasil

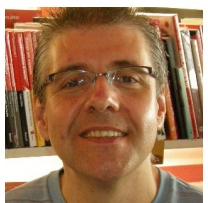

Carlos Alberto de Carvalho <carloscarvalho0209@gmail.com>

Programa de Pós-Graduação em Comunicação da UFMG

Avenida Antônio Carlos, 6.627 - Campus Pampulha

31270-901 - Belo Horizonte (MG) - Brasil 